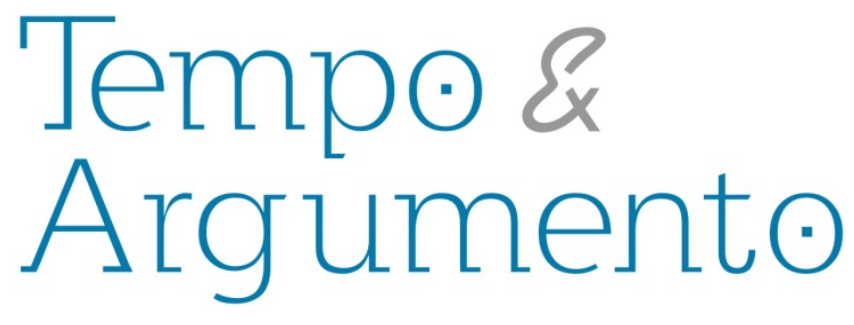

\title{
Histórias de municípios narradas nos seus sites oficiais: a História Pública e seu potencial para a pesquisa histórica
}

\begin{abstract}
Resumo
Parte-se do princípio de que as representações históricas presentes em sites municipais oficiais possibilitam um significativo e pouco explorado caminho para a análise e produção de conhecimento histórico. A partir das contribuições da História Pública, o artigo tem por objetivo problematizar o conteúdo histórico dos sites dos 25 municípios integrantes da Comunidade dos Municípios da Região de Campo Mourão (COMCAM). Metodologicamente, o estudo se pauta no entendimento do conteúdo dos sites enquanto fontes históricas, avaliadas naquilo que eles indicam sobre os seus tipos de narrativas, e sobre os silenciamentos e as lacunas, bem como sobre seus usos potenciais na pesquisa histórica. Com a problematização desse material, visa-se contribuir com uma análise epistemológica a respeito das categorias memória e identidade.
\end{abstract}

Palavras-chave: Campo Mourão (PR); Municípios História. Sites da Web - Avaliação e Classificação.

\author{
Jorge Pagliarini Junior \\ Doutor em História pela Universidade Federal da \\ Grande Dourados. Professor do curso de \\ História e do Programa de Mestrado Profissional \\ em Ensino de História -PROFHISTÓRIA da \\ Universidade Estadual do Paraná. \\ Brasil \\ palhajr@yahoo.com.br
}

\section{Para citar este artigo: \\ PAGLIARINI JUNIOR, Jorge. Histórias de municípios narradas nos seus sites oficiais: a História Pública e seu potencial para a pesquisa histórica. Revista Tempo e Argumento, Florianópolis, v. 9, n. 20, p. 247 - 266. jan./abr. 2017.}

DOI: $10.5965 / 2175180309202017247$

http://dx.doi.org/10.5965/2175180309202017247 


\title{
Histories of cities narrated on their official websites: the Public History and its potential for historical research
}

\begin{abstract}
In this study, it is assumed that the historical representations present in municipal official websites allow a significant and little explored way for the analysis and production of historical knowledge. Based on the contributions of Public History, the article aims to problematize the historical content of the websites of the 25 municipalities that integrate the Community of Municipalities of the Campo Mourão Region (COMCAM). Methodologically, the study focuses on the understanding of the content of the websites as historical sources, evaluated on what they indicate about their types of narratives, and on the silencing and gaps as well as their potential uses in historical research. With the problematization of this material, it is intended to contribute with an epistemological analysis regarding the categories of memory and identity.
\end{abstract}

Keywords: Campo Mourão (PR). County - History. Websites

- Evaluation and Classification.

\section{Sites municipais: da pesquisa, seus alcances e suas projeções}

Nosso diálogo parte dos conteúdos históricos de sites municipais, sites esses considerados aqui como fonte para a produção de um conhecimento histórico direcionado à pesquisa local/regional. Tendo por ancoragem a História Pública, nossas preocupações teóricas e epistemológicas apontam para a revisão do campo da História mediante a análise e a reflexão em torno dos usos e dos significados da narrativa histórica voltada para o grande público, não especialista, nas suas implicações na relação entre história, memória (esquecimento) e identidade. 
A construção do texto que segue está estruturada em dois momentos, sendo o primeiro referente ao tratamento do objeto e da metodologia da pesquisa, num diálogo com o campo da comunicação, com o paradigma regional e com a História Pública (três primeiros subtítulos). O segundo tem por foco a apresentação específica dos dados levantados e das leituras epistemológicas deles resultantes e contempla, por fim, a apresentação de possiblidades de usos do material pesquisado.

Iniciemos com a constatação de que nosso projeto se fundamenta no diálogo com o campo da comunicação. Nosso posicionamento a respeito do conteúdo histórico de produtos midiáticos vai da interpretação da crítica orweliana (MAGNO, 2014), aqui reapropriada a partir da análise das formas como as memórias passam a ser repensadas diante das tecnologias midiáticas, leitura pautada nas interpretações da obra intitulada "1984" - obra baseada na opressão dos regimes totalitários das décadas de 1930 e 40² e chega, recentemente, nas dinâmicas que rodeiam a construção de um diálogo demarcado dentro da área da História e de disciplinas afins, o da História Pública.

Especificamente, nosso estudo analisa como os 25 municípios que compõem a região da Comunidade dos Municípios da Região de Campo Mourão - COMCAM apresentam suas histórias nas suas respectivas páginas oficiais (sites). Parte-se do pressuposto segundo o qual a internet, quando utilizada como veículo oficial de comunicação, serve à construção de determinadas leituras - digam-se, discursos - do passado. Essas construções ora procuram sintetizar discursos presentes nas memórias e representações sobre a história dos lugares, ora projetam leituras que se pretendem tornar oficiais.

A título de encaminhamento da leitura, podem-se apresentar como nossos objetivos: i) analisar a construção dos sites dos municípios que compõem a Comunidade dos Municípios da Região de Campo Mourão (COMCAM); ii) caracterizar os possíveis silenciamentos a partir da interpretação dos textos selecionados; iii) analisar as diferentes

\footnotetext{
${ }^{1}$ Cabe ressaltar que o artigo apresenta recortes de uma pesquisa maior, iniciada no ano de 2015 em forma de projeto de Iniciação Científica e continuada no ano de 2016 com o agregado de novas demandas de leituras mediante projeto de pesquisa.

2 Tendo como protagonista a personagem de Winston Smith, membro do partido externo, funcionário do Ministério da Verdade e encarregado de reescrever a história de acordo com o interesse do Partido.
} 
formas de linguagens empregadas nos sites estudados; iv) analisar as matrizes e os desafios da História Pública; vii) problematizar o emprego de conceitos de comunidade, identidade e pioneirismo nos conteúdos dos sites.

\section{Composição da COMCAM}

A COMCAM é composta por 25 municípios, a saber: Altamira do Paraná, Araruna, Barbosa Ferraz, Boa Esperança, Campina da Lagoa, Campo Mourão, Corumbataí do Sul, Engenheiro Beltrão, Farol, Fênix, Goioerê, Iretama, Janiópolis, Juranda, Luiziana, Mamborê, Moreira Sales, Nova Cantu, Peabiru, Quarto Centenário, Quinta do Sol, Rancho Alegre D`Oeste, Roncador, Terra Boa e Ubiratã. Quanto aos seus objetivos, consta no seu próprio site: "fundada em 30 de julho de 1969 e institucionalizada em, 26 de fevereiro de 1986, é a organização não governamental encarregada de promover integração administrativa, econômica e social dos municípios situados na região de Campo Mourão [...]" (COMCAM, 2014) $)^{3}$.

A escolha do recorte espacial da pesquisa deveu-se à possibilidade de avaliar a proposta de unidade e de paridade administrativa defendida nos propósitos da COMCAM (COMCAM, 2014), com narrativas históricas presentes nos sites. Dessa forma, o recorte espacial da pesquisa corresponde à delimitação territorial da região da COMCAM, todavia não foi essa entidade o objeto de estudo, mas, sim, os sites de municípios que a compõem. Já o recorte temporal corresponde ao próprio momento da análise da configuração dos sites - história do tempo presente - sem se voltar necessariamente ao estudo das suas reconfigurações. Essa delimitação não impede a análise do momento de formatação dos sites - meados da década de 1990 -, bem como dos marcos temporais que servem de referencial histórico para a maioria dos sites, temáticas caras aos históricos municipais, e, já podemos adiantar, direcionadas ao período entre 1940 a 1960, momento das emancipações dos municípios.

\footnotetext{
${ }^{3}$ Cabe ressaltar que, entre os 25 sites, apenas de um deles não consta o endereço eletrônico na página da COMCAM e, entre eles, todos possuem um campo referente à história do município. Para o estudo desses canais de comunicação, o que se pretende é avaliar os tipos de interpretação histórica apresentados, abrangendo com isso as suas formas de narrativas e, principalmente, as projeções históricas construídas/reproduzidas.
} 
O debate do assunto nos remete ao desafio de pensarmos a renovação do paradigma regional. Atentando aos processos desiguais e à produção resultante da nossa pesquisa histórica, lidamos com as identidades enquanto sinônimas de construções históricas, permeadas por discursos, por disputas e por silenciamentos.

A propósito de como isso repercute no nosso posicionamento epistemológico, cabe uma aproximação com Martins (2010), e então percebemos que o espaço, ou o seu recorte, mais do que uma delimitação espacial, se relaciona em redes de interação social, seja no tocante ao vivido, seja no tocante aos jogos de escalas identificados em meio ao estudo de fenômenos sociais. Martins no referido estudo problematiza as limitações de um modelo de história regional que apenas reproduzisse o debate nacional, numa perspectiva tradicional em uma escala espacial menor, sem com isso questionar a estrutura e a própria construção e análise histórica dos sujeitos inseridos. 0 questionamento dessas estruturas contribui para o entendimento do emprego das paráfrases que constituem os textos históricos dos sites.

\section{Comunicação e História Pública}

No tocante ao diálogo com a comunicação, entende-se aqui a mídia num processo dialético no qual ela influencia e é influenciada pelo social. Quanto a essa afirmação, para ela serve de respaldo científico a homogeneização do cotidiano. A respeito dessa credibilidade amparada na "vontade de verdade", Foucault destaca que não se trata "[...] das verdades que constrangem: História dos planos de objetos de conhecer, história das funções e posições de sujeito cognoscente, história dos investimentos materiais, técnicos, instrumentais do conhecimento" (FOUCULT, 1996, p. 17). Dessa maneira, a abordagem histórica aproxima-se do campo da comunicação e da sociologia, e das interfaces (sites) na sua lógica diante das demandas dos municípios.

Mesmo que sejam aqui considerados debates específicos ao campo da comunicação, bem como o impacto das novas tecnologias nas pesquisas históricas, devemos nos posicionar diante do fato de falarmos a partir da História Pública, um campo de debate solidificado no Brasil na última década. Nas palavras de Ricardo Santhiago 
(2016), História Pública é um lugar de debate pensado pela assimilação, sem, necessariamente, simplificação do conteúdo histórico; uma história produzida do entrecruzamento entre: a ampliação de audiências, o caráter colaborativo, a atenção às formas não institucionais de história e memória e a autorreflexividade do campo, ou seja, respectivamente, a história feita para o público, a história com o público, a história pelo público e a história e público (SANTHIAGO, 2016. p. 28).

Da mesma forma, é pertinente ao conhecimento desse campo o questionamento do significado do conceito de púbico, conforme alerta a historiadora Renata Schittino (2016). A autora revisita, por exemplo, a definição de Arendt sobre “público”, concepção que, numa primeira abordagem, remete ao visível e ao público (ver e ser visto, ouvir e ser ouvido, acepção aristotélica por ela adotada) como um lugar de igual para os iguais, mas ampliado pela importância da diferença entre o publicizável e o íntimo, e, portanto, algo próximo do pluralismo e da necessidade do espaço de aparência para nossa realidade. Numa segunda concepção, Arendt, segue a autora, aponta para a hierarquização do real, e da sua crítica à modernidade problematiza como, na sociedade moderna, ou seja, na sociedade de massa, a esfera pública passa a se sustentar como "[...] uma espécie de indivíduos privados" (SCHITTINO, 2016. p. 42). Ou seja, perda do mundo comum e prevalência do mundo privado, contexto em que o privado e o público vão se salvaguardando na imagem do Estado (ibidem). A autora problematiza o aparecimento da esfera pública burguesa, buscando, entre outros, em Habermas; este, diferente de Arendt, lembra a autora, positiva aspectos de esfera pública - tese controversa, segundo ela, ressaltando que, mesmo com a perda do caráter crítico da esfera pública, ela ainda se mantém como um ambiente propício para o crescimento da crítica argumentada (SCHITTINO, 2016. p. 44). Chega-se ao público ligado ao Estado e ao público ligado ao grupo de pessoas privadas.

Nas conclusões do capítulo, a autora retrata o suposto "[...] esvaziamento do espaço público e/ou da esfera privada sobre a esfera pública e enfatiza o papel do historiador diante da popularização do espaço público, atuando, assim, entre a ciência altamente especializada com o cotidiano" (SCHITTINO, 2016. p. 45). Nas palavras da 
própria autora ao tratar daquilo que denominou "via moderna" do espaço público, o historiador entenderá a História Pública onde há a História acadêmica, científica:

[...] não encarna a posição de juiz do passado, mas parece como farol de luz mediante uma incompreensão de mundo, e não toma para si a tarefa de desenvolver a consciência histórica levando ao público leigo - a questão - me parece não se coloca nos termos de história pública versus história acadêmica; e tampouco como a querela entre ciência e relativismo. Pensar a noção de público como compartilhamento nos permite vislumbrar - e acho que isso é uma aposta de certo modo - mas, então, acho que o compartilhamento nos deixa ver que a questão da história pública é menos uma questão de fronteira - de demarcação de fronteira e mais uma possibilidade de olharmos para os lados, para cima, para baixo e assumirmos esse mundo comum como um diálogo possível. (SCHITTINO, 2016. p. 46).

A propósito da ressignificação de tal crítica na pesquisa por nós ora apresentada, acreditamos que as formas como as prefeituras apresentam, nos seus sites, a história do município possibilita um caminho para a problematização da concepção de história reafirmada nesses canais oficiais de comunicação.

Cabe então aqui uma aproximação com os nossos procedimentos metodológicos. Em linhas gerais, a discussão considera a análise de um corpus que, evidentemente, não fora produzido para a finalidade de estudo acadêmico.

Ao nos apropriarmos das categorias de discursos (discursos autoritário, polêmico e lúdico), tomamos o cuidado de não construir um modelo puro. Um dos caminhos para a análise seguiu mediante a análise dos discursos, compreendida na pesquisa num posicionamento próxima ao de Orlandi (1999). Segundo a autora, a compreensão de um discurso envolve a análise de signos a partir do lugar de encontro entre língua e ideologia ou, ainda, entre os campos da Linguística, do Marxismo e da Psicanálise (ORLANDI, 1999), ou seja, diante da análise dos dispositivos teóricos. A interpretação dos dispositivos teóricos e analíticos deverá considerar, antes de tudo, o próprio sujeito e sua forma histórica, delimitada no tempo e no espaço, e levar em conta as condições de produção e o interdiscurso, os esquecimentos, a paráfrase e a polissemia; assim como as formações imaginárias, a formação discursiva, a ideologia, além das formas internas de controle do discurso. A propósito da Ideologia, a autora atenta ao apagamento do processo de 
produção, ressaltando a importância do imaginário com o qual os aparelhos lidam e buscam silenciar. No tocante à preocupação analítica do social, afirma, quanto ao social: “[...] não são os traços sociológicos empíricos - classe social, idade, sexo, profissão - mas as formações imaginárias que se constituem a partir das relações sociais que funcionam no discurso: a imagem que se faz de um pai, de um operário, de um presidente, etc." (ORLANDI, 1999. p. 56). O debate parte dessa abordagem metodológica e nos remete, mais uma vez, ao estudo da História Pública, ou, aqui, à relação entre História Pública e imprensa.

Mesmo que atentemos, nesta escrita, unicamente ao conteúdo histórico dos sites, outros campos foram avaliados, por exemplo, os tipos de colunas e de informes e seus respectivos discursos, tempo de atualização das páginas. Assim, portanto, entendemos os sites oficiais como ferramentas de comunicação, ferramentas próximas, em certo sentido, dos propósitos de jornais on-line, mesmo porque, na maioria dos sites destacados, regulamenta-se um canal de notícias on-line.

Ao tratar das preocupações epistemológicas e metodológicas da História Pública, Marialva Barbosa (2016) relaciona as áreas de História e de Comunicação, avaliando a autoatribuição que se dá a si mesma a imprensa e o seu lugar frente aos usos do passado nas suas estratégias narrativas, frente ao imediatismo da imprensa, tratada como arquivo pelo pesquisador. Na mesma obra a autora problematiza como os textos dos periódicos se encontram permeados pela "força do presente", um presente acelerado, imbuído de futuro, no qual o passado se torna assim o tempo diferente, novo. Nessa seara, a autora discute com regimes de historicidade e com as concepções de tempo - presente, passado e futuro -, tendo por foco o "passado no presente"4; avalia ela então, por exemplo, as razões de seu uso, os mapas dos usos e os devidos cuidados a serem considerados pelos envolvidos no estudo histórico da imprensa (BARBOSA, 2016. p. 123). Caberia assim aferir, diante das estratégias de usos do passado, a fundamental participação da imaginação produtiva aplicada do presente ao passado, processualmente

\footnotetext{
${ }^{4}$ Os recortes do passado, realizados no intuito de um presente que quer contemplar o futuro, e, portanto, um passado "alargado", pautado na apresentação de um passado linearmente atrelado ao presente e que, na pretensão de verdadeiro, tem caráter genealógico, defende a autora (idem).
} 
Soma-se a essa releitura dos regimes de historicidade aplicados aos periódicos o fato de a História Pública interessar-se pela história digital, conforme alerta Michael Frisch (2016), pioneiro nos estudos públicos nos EUA. Ao se posicionar a partir de suas pesquisas com a História Oral, Frisch defende a proposta de uma "autoridade compartilhada", tomada pela metáfora da dicotomia entre o "cru e o cozido", na qual o cru pode ser pensado pelas dificuldades de acesso ao material decorrente de transcrição de entrevistas, e o cozido, dos resultados de novas tecnologias de acesso às fontes e, por isso mesmo, ao debate compartilhado da História Pública. Da relação entre o "cru e o cozido", Frisch apresenta exemplos inspiradores do uso de tecnologias on-line e chega à reflexão a respeito da diferença entre o buscar - na internet - e o explorar (FRISCH, 2016). Quiçá tal compartilhamento estivesse presente nas páginas de outros sites, sobretudo no campo referente ao histórico do município; algo distante da atual configuração e modus operandi dos sites estudados.

\section{Alguns resultados}

O estudo do processo de produção dos conteúdos históricos dos sites e suas releituras envolve atenção àquilo que François Hartog (1996) denomina de "Regime de Historicidade". Em muitas das vezes, os sites apresentam formas de escritas estruturadas em três concepções, sendo elas a História enquanto "mestra da vida", carregada, por exemplo, do discurso do pioneirismo; a presentista, voltada às realizações de um curto recorte, via de regra correspondente ao mandato da gestão atual; e, ainda, a teleológica, estruturada numa projeção das demandas e dos acontecimentos das conquistas políticas (científicas, morais, etc.) representadas nos programas políticos. A análise dos discursos históricos pauta-se nessas formas de história representadas. A discussão se complementa com o estudo das formas de escrita e suas figuras de linguagens.

Tomados de tais reflexões, na sequência apresentamos um questionário - a partir do qual produzimos uma tabela de balizamento das análises dos sites - e da sua 
interpretação encaminhamos o debate. O questionário contém os principais comparativos e as diferenças entre os 25 sites e está dividido em duas modalidades, sendo uma delas referente às questões de layout e da manutenção dos sites e outra referente aos conteúdos históricos presentes (nossa abordagem central neste artigo).

\subsection{Quanto ao layout:}

i) Desde quando o site está no ar? (contatar a prefeitura)

ii) Quando ocorreu sua última reformulação? (contatar a prefeitura)

iii) Quando ocorreu sua última atualização? (contatar a prefeitura)

iv) Com qual periodicidade o site é atualizado? (contatar prefeitura)

v) Alguém assina pelo site?

vi) Possui um canal de comunicação on-line? (estabelecer contato via site e indicar tempo de recebimento da resposta)

vii) Caso exista, os contatos com o administrador do site ficam disponíveis a todos aqueles que acessam o site?

viii) Algum outro campo ou link apresenta leituras históricas? (exemplificar) ou fotografias, artigos, homenagens, etc.)? (especificar)

ix) Conta o campo específico da história do município com fácil acesso e localização no site?

x) Existe algum destaque imagético da página de abertura cujo conteúdo remeta a leituras históricas? Exemplificar.

xi) Ao destacar informações da atual gestão (canal on-line), utiliza alguma conotação histórica? (comparativo com outras épocas, homenagem a pioneiros e personalidades, etc.) Exemplificar.

xii) Além de textos escritos, existem outros tipos de narrativas que retratam conteúdos históricos? (fotografias ilustrações, charges, etc.) Exemplificar. 


\subsection{Quanto ao conteúdo de História:}

i) Foi ou é a sua produção auxiliada por algum historiador? (contatar prefeitura)

ii) Apresentam os textos de caráter histórico alguma problemática ou são meramente informativos?

iii) Possui o texto histórico referências bibliográficas? (caso possua, citar)

iv) Apresentar uma síntese de um parágrafo sobre a abordagem da história do município (recorte de tempo e de espaço; destacar se o site conta a história a partir da política, do econômico, da cultura? Faz alguma homenagem ou destaca personalidades? Destaca o papel de pioneiros? Utiliza datas significativas? A narrativa faz alguma referência aos moradores do município? E aos "sujeitos comuns"? Conta a História numa narrativa trágica? Cômica? Romanesca? Apresenta mitos locais/regionais?)

v) Apresenta o conteúdo histórico uma leitura histórica teleológica? Utiliza a história como magistra vitae? Apresenta uma leitura presentista da História? Exemplificar.

Apenas um dos municípios não apresenta um histórico. A propósito dos demais, por ora, numa tentativa de síntese e considerando as caraterísticas deste artigo, cabe ressaltar: apenas um dos sites apresentou autoria da página (Campina da Lagoa); dois deles citam contribuições de colaboradores na sua produção - pesquisa histórica, sendo um deles o de Campina da Lagoa, no qual se apresenta o acervo de um morador e historiador local, e o de Janiópolis, no qual se apresentam as contribuições da professora de História do colégio local. Apenas estes dois últimos municípios apresentam a sua metodologia - no caso, o da produção de entrevistas e/ou pesquisa em acervos de moradores; outro município apresenta fragmentos de entrevistas com moradores intitulados pioneiros - (Rancho Alegre do D’Oeste), no entanto, ele não se posiciona quanto à metodologia empregada. Apenas um município apresenta referência bibliográfica no seu texto (Barboza Ferras), e dois outros, a autoria do texto (Campina da lagoa e Nova Cantú). 
Seis deles continham inúmeros erros de sintaxe e/ou de semântica nos seus textos. Nove possuíam outros campos/links que não o referente ao da História do munícipio nos quais também se encontram informações sobre fenômenos históricos locais, como acontecimentos, eventos, festas, história de lugares; esses campos estavam intitulados por “pratos típicos”, “atrações turísticas”, “paisagem”, “curiosidades”, “linha do tempo", “o gentílico”, "emancipação política” e deles cabe ressaltar que, em alguns casos, o espaço e as problematizações a eles destinados eram, inclusive, maiores e mais completos do que o destinado ao texto sobre a História.

Todos os sites apresentam um recorte específico sobre a sua colonização e emancipação política; no seu conjunto, 23 sites informam a data da colonização entre a década de 1920 e a 1940, e o da sua emancipação política entre 1940 e 1950; em apenas dois municípios as emancipações ocorreram na década de 1980, sendo que, neles, o período da colonização foi o mesmo dos demais.

Apenas três municípios deixam de apresentar uma genealogia do seu nome. Sete municípios possuem imagens históricas; destes, apenas três possuem legendas nas imagens (Campina da Lagoa, Nova Cantú e Roncador). Dez sites não fazem relação entre a sua história e a história do Paraná e/ou do Brasil; nos demais, desta relação são marcantes as temáticas: século XVI, com o histórico das cidades espanholas (Barbosa Ferraz, Campo Mourão e Fênix); da lendária estrada de São Tomé e Príncipe e do lendário caminho do Peabiru (Araruna, Campo Mourão e Peabiru); das reduções jesuíticas e da ação dos bandeirantes (Barboza Ferras e Peabiru). Referente ao século XIX: com a expedição de Afonso Botelho (Campo Mourão); com as atividades realizadas por paraguaios-ervateiros anteriores ao processo de ocupação pelos brasileiros (Campina da Lagoa); da estrada Boiadeira e da ligação do Paraná com Mato Grosso (Altamira do Paraná); das rotas de tropeiros (Campo Mourão). Referente ao século XX, com os minifúndios resultantes da colonização da década de 1930 (Iretama); com o trabalho dos safristas com a madeira (Nova Cantú); com o cultivo da hortelã (Barbosa Ferraz); com a gestão cultural (Campo Mourão) e com as instituições universitárias (Campo Mourão e Goioerê). 
Sobressai então a temática do pioneirismo. Apenas dois municípios deixam de fazer referência direta aos pioneiros e suas famílias (Barbos Ferraz e Fênix). Nove municípios não contam a história da sua ocupação numa narrativa romanesca, deixando de enfatizar como os demais assim o fazem as adversidades atreladas ao processo de desbravamento das matas. Apenas seis munícipios fazem alguma menção à presença indígena nas suas terras durante o período da colonização (Araruna, Barbosa Ferraz, Boa Esperança, Fênix, Peabiru e Ubiratã). Apenas um município trata de conflitos relacionados à ocupação de suas terras (Peabiru); outro município destaca algumas lendas e/ou mitos (Juranda).

Tal análise de conteúdo e de suas formas narrativas se amplia com a apresentação do embasamento epistemológico a partir do qual analisamos as categorias norteadoras de nossa pesquisa. Dessa maneira, na abordagem conceitual e histórica do conteúdo dos sites nos interessam diretamente duas categorias, quais sejam: memória e identidade.

A potencialidade dos sites frente aos processos de reificação e de esquecimento implica diretamente as identidades mapeadas na pesquisa aqui apresentada. Tomamos identidades num sentido próximo ao adotado por autores que debatem identidades a partir das suas implicações de ordem da linguagem e das relações de poder- leia-se, discursivas (Candau, 2011; Hall, 2014; Woodward, 2014; Silva, 2014;). Nesta perspectiva os sites possibilitam o entendimento de caminhos de análises voltadas para a interpretação de sistemas de classificação, e não apenas isso, voltados às representações sociais. Um esforço atento, por exemplo, ao reconhecimento de que a linguagem "vacila" (SILVA, 2014. p. 78). As clivagens, a demarcação das diferenças, o espaço para o híbrido são elementos que ganham destaque em nossas leituras.

Alguns sites apresentam, no seu passado, a construção comunitária. Trabalhar com o conceito de comunidade, conforme aponta Bauman, requer certos cuidados: “[...] tipo de mundo que não está, lamentavelmente, ao nosso alcance - mas no qual gostaríamos de viver e esperamos vir a possuir. Raymond Williams, atento analista de nossa condição comum, observou, de modo cáustico, que o que é notável sobre a comunidade é que 'ela sempre foi"' (BAUMAN, 2003, p. 9). Acreditamos que diante do estudo dessas tentativas de homogeneização do passado, conforme destacou Candau 
(2011. p. 30-59), não devemos desconsiderar a diferença entre a memória manifestada e a memória lembrada, ou seja, entre a memória pautada no vivenciado e a no semântico, sobretudo quando avaliamos o grau de pertinência de memórias holísticas.

A propósito dessa memória comunitária reificada, avaliamos sua pertinência a partir da categoria identidade. E, para fundamentar melhor nossa análise, trazemos aqui a relação entre memória e identidade. Tal debate parte da própria apresentação dos limites daquilo que Candau (2011) denominou narrativas holísticas, no caso dos sites e em acordo com estudos por nós já realizados, relacionadas ao papel do Estado na colonização e à participação de pioneiros que teriam contribuído com o desenvolvimento do "Oeste histórico", pautado nas narrativas dentro da "Marcha para o Oeste", esta vivida em nível nacional nas décadas de 1940 a 1970. E muito das informações contidas nos sites oficiais apresentam uma construção memorialista, que se pretendem memórias coletivas: "Os atos de memória decididos coletivamente podem delimitar uma área de circulação de lembranças, sem que por isso seja determinada a via que cada um vai seguir" (CANDAU, 2011. p. 35). Complementa Candau: "Algumas vias são objetos de uma adesão majoritária, mas memórias dissidentes preferirão caminhos transversais ou seguirão outros mal traçados. Assim, o compartilhamento memorial será fraco ou quase insistente" (ibidem). Em síntese, uma disputa entre as memórias fortes e fracas ${ }^{5}$. Desta relação o autor trabalha com a memória genealógica, a memória geracional, a memória da tragédia, a prosopopeia memorial, entre outras formas de memória analisadas em sua obra.

A citação posiciona o lugar das tensões representadas pelos discursos históricos dos sites. E se as "memórias fortes" organizam a grande maioria das narrativas, não podemos atestar com isso a inexistência de narrativas que recorreram àquilo próximo ao

\footnotetext{
${ }^{5}$ Em que pese aqui a diferenciação epistemológica de Candau (Idem) entre a memória coletiva e a memória compartilhada. Para o autor, a memória não pode ser coletiva, pois, mesmo considerando a interferência das metanarrativas nos habitus - "protomemória”, para Candau, a "memória propriamente dita", segunda categoria de seu modelo explicativo das memórias, justamente pela sua potencialidade de análise e apropriação, composta de sutileza e propícia ao movimento da resistência frente aos discursos holístico, impediria que assim se pudesse considerar metanarrativas enquanto memória(s) individual(ais). Tal diferenciação entre a memória socialmente partilhada da coletiva nos auxilia diante do exercício de análise dos conteúdos histórico dos sites, sobretudo na tentativa de críticas ao movimento de generalização entre memória - na verdade, da metanarrativa - e a história. Ainda próximos ao autor podemos considerar as estratégias de construção de memórias holísticas, representadas nos discursos do colonizador pacífico, ordeiro, comprometido com o desenvolvimento regional via transformação da natureza local.
} 
que o autor intitula "memórias fracas". Por exemplo, as excentricidades locais, como o marco a partir do qual uma tragédia policial vivida em um dos municípios repercutiu no estado e fora decisiva para a criação de determinado grupo especial da polícia (Goioerê). Outras abordagens se destacam, sendo o caso da defesa de política de regularização fundiária sobre a qual se assume uma crítica direta aos posseiros (Luiziania); ou mesmo o da positivação do fato de o município possuir um grande percentual de minifúndios em decorrência das suas caraterísticas morfológicas - terrenos acidentados (Iretama). Também nos chamaram a atenção os temas como: parques ecológicos e o IDH; curiosidades presentes nas genealogias de alguns nomes de municípios; a especificação de culturas, como a da hortelã; da mesma forma, a presença indígena e, em um caso, suas lendas; também, em outros, as lendas (visões, previsões, etc.) dos colonizadores. Isso tudo e mais o fato já indicado de que um dos municípios apresenta fragmentos de entrevistas relacionadas ao cotidiano da colonização.

Quanto ao esquecimento, reconhecemos que, ao reificarem certas memórias, os sites se tornam mecanismo de esquecimento. Mesmo assim, no entanto, a conotação crítica da afirmativa pode ser atenuada quando recorremos a Paul Ricoeur (2007) com a sua conceituação da relação entre História, memória e esquecimento, obra na qual direciona o debate ao caráter narrativo desse conhecimento. Nisso o autor retoma o significado de debates clássicos, como as contribuições da Psicanálise, as críticas ao próprio sentido de História lançadas por Nietzsche e o debate contemporâneo com Certeau a respeito da "operação histórica" (RICOEUR, 2007) ${ }^{6}$. Especificamente no tocante ao esquecimento, destaca o autor como os "abusos" fundamentam a conflituosa relação entre historiografia e memória. Esses abusos não refletem pura e simplesmente algo negativo à investigação histórica, e a própria historiografia prestaria um serviço à memória?.

\footnotetext{
${ }^{6}$ Da relação entre história, memória e esquecimento ressalta-se, nessa obra, a operação histórica, numa construção dialogal, composta de três fases complementares entre si, sendo elas a fase documentária, a da explicação/documentação e a da representação.

7 Quando Ricoeur aborda aquilo que intitula "a face cognitiva da memória", alerta para a imbricação da memória e da imaginação. Segundo ele, a imaginação pode travestir-se astuciosamente de memória e, se bem utilizada, pode contribuir na interpretação do passado (sendo o caso da imaginação histórica). Trata-se da própria seletividade da memória. A operação histórica de construção do conteúdo histórico dos sites, do significado das fontes, ou, na maioria dos casos, da sua ausência, a escrita e recepção e a relação entre memória e imaginação permearam nossa análise conceitual.
} 
Numa abordagem próxima a de Ricoeur, a análise dos conteúdos históricos dos sites implica avaliar o significado de uma construção dialógica que venha a fundamentar análises históricas e, com isso, necessita de um olhar atento não apenas ao visível, mas também às memórias subterrâneas, memórias do trauma e, respectivamente, aos silenciamentos que envolvem sua produção (POLLAK, 1989).

\section{Mais diálogos}

Na sequência, a partir da apresentação de mais pesquisas por nós produzidas exemplificaremos algumas análises das narrativas de sites municipais. Antes, porém, vale ressaltar, por conta da estrutura do artigo, que não faremos a problematização da metodologia e dos resultados desses projetos, restringindo-nos à sua apresentação. As atividades se dividem em duas experiências de pesquisas estruturadas no e pelo ensino de História - outro significativo campo de leitura da História Pública, diga-se de passagem. $^{8}$

Incialmente podemos indicar um conjunto de cinco trabalhos realizados no Programa de Desenvolvimento Educacional do Paraná (PDE) ${ }^{9}$, cada um deles referente ao estudo de um município da região da COMCAM, no qual conhecemos mais das cidades e dos discursos públicos nos e pelos sites, de maneira a apresentar aos professores - alunos do programa de formação e as turmas envolvidas na intervenção - um estudo a partir do qual pudemos potencializar e problematizar as leituras históricas desses lugares, seus

\footnotetext{
${ }^{8}$ Outro exemplo de pesquisa no qual empregamos o estudo dos sites remete ao nosso processo de doutoramento e à temática da migração, no qual estudamos munícipios outros que não esses da região da COMCAM. Trata-se de munícipios do Oeste do Paraná, e de municípios da Amazônia Legal, das unidades federativas do Mato Grosso, de Rondônia e do Pará. A pesquisa concentrou-se na problematização do fenômeno da migração de retorno, e os conteúdos dos sites nos serviram ao exercício de cotejamento das entrevistas orais por nós produzidas. Seus usos indicaram, por exemplo, para os significados da positivação da migração sulista, presente nos sites de cidades da Amazônia Legal, e do discurso de positivação do trabalho agrícola no PR, o "celeiro do Brasil" no outro, das cidades do Oeste do Paraná, lugares de onde saíram e para onde retornaram os nossos entrevistados. Isso sem mencionar outras formas de problematização de discursos de época e atuais (2014), além de contribuir como suporte para informações sobre o processo e as realidades históricas regionais. Devido ao recorte do artigo não problematizaremos tais experiências metodológicas

9 Programa de Formação Docente Continuada oferecido aos professores da rede pública no qual esses professores, no período de dois anos, produzem, entre outros produtos, um material didático, a ser utilizado nas suas aulas de intervenção nos colégios.
} 
discursos e seus silenciamentos. Trata-se de atividades também produzidas no Programa de Bolsas de Iniciação à Docência (Pibid) e, numa delas, inclusive, tendo como objetivo produzir uma contrapartida aos discursos do site de um munícipio da COMCAM, propomos a construção de um blogue pelos próprios alunos, local virtual no qual foram apresentadas outras e mais intepretações da história local - do munícipio e dos familiares, ou mesmo da instituição escolar, lançando-se mão de diferentes fontes, e sendo o material resultante dessa atividade disponibilizado on-line.

Os projetos realizados citados acima foram concluídos nos últimos cinco anos, portanto, alguns são anteriores inclusive à pesquisa que aqui apresentamos como objeto do artigo. Novas propostas de usos e de discussões dessa temática e da sua metodologia se encontram em andamento, todas, conforme defendemos até o momento, ancoradas no potencial da História Pública, nas especificidades de cada pesquisa.

\section{Algumas considerações}

Os sites municipais nos serviram de ponto de referência para o estudo das identidades regionais materializadas pelos discursos oficiais municipais. O processo que envolve a tentativa metamemorial de influenciar naquilo que se deve lembrar e naquilo que se deve esquecer implica um estudo de identidades. O estudo do discurso do pioneirismo; a maneira como os sujeitos históricos lidam com a natureza, numa perspectiva transformadora e inserida numa lógica de progresso herdeira da "Marcha para o Oeste"; as peculiaridades históricas locais; e ainda as formas de narrativas nortearam nossas intepretações. Um último exemplo: no site do município de Rancho Alegre d'Oeste alerta-se para o fato de que as entrevistas ali citadas representam histórias verídicas, narradas por pioneiros. Neste caso, a autoridade da entrevista corrobora a problemática até aqui discutida, a da representação de um passado homogêneo, no qual a memória é tomada como sinônimo de história, tendo-se por pano de fundo as adversidades e as alegrias do período selecionado a partir do recorte da ocupação/colonização. 
Nossas leituras enveredaram-se para os propósitos da História Pública, numa aproximação via apresentação de resultados de pesquisa. E estes resultados representam um material em potencial, possível de ser analisado e disseminado mediante o trabalho com as diferentes tendências da História Pública. Cabe ainda a necessidade de se avaliarem estratégias de disseminação deste material no intuito de que seu alcance e graus de engajamentos não permaneçam restritos ao tradicional território do historiador.

Concluindo, vale ressaltar que reside no nosso texto uma constatação implícita de que se, por um lado, os sites apresentam o interesse da quase totalidade dos municípios estudados em apresentarem determinada versão de sua história, por outro, carecem de um olhar profissional, quiçá do historiador, no desenvolver de pesquisa, na sistematização dela e na construção de textos. Ancorado no potencial da História Pública, o processo de inserção de historiadores nesses veículos de comunicação municipais se tornaria importante, inclusive, para a afirmação profissional dos historiadores formados na região.

\section{Referências}

BARBOSA, Marivalda. Imprensa e história pública. In: MAUAD, Ana Maria; ALMEIDA, Juniele Rabêlo de; SANTHIAGO, Ricardo (Orgs.). História Pública no Brasil: sentidos e itinerários. São Paulo: Letra e Voz, 2016. p. 121-132.

BAUMAN, Zygmunt. Comunidade. Rio de Janeiro: Jorge Zahar, 2003.

CANDAU, Joël. Memória e identidade. São Paulo: Contexto, 2011.

CHARTIER, Roger. O mundo como representação e a história entre narrativa e conhecimento. In: CHARTIER, Roger. A beira da falésia: a história entre certeza e inquietude. Trad. Patrícia Chitoni Ramos. Porto Alegre, RS: EUFRGS, 2002. p. 61-100.

COMCAM. [site]. Campo Mourão, PR, 2014. Disponível em: <http://www.COMCAM.com.br/site/>. Acesso em: 25 fev. 2014. 
cozinha digital, e vice-versa. In: MAUAD, Ana Maria; ALMEIDA, Juniele Rabêlo de; SANTHIAGO, Ricardo (Orgs.). História Pública no Brasil: sentidos e itinerários. São Paulo: Letra e Voz, 2016. p. 57-70.

HALL, Stuart. Quem precisa de identidade? In: SILVA, Tomaz Tadeu da. (Org). Identidade e diferença: a perspectiva dos estudos culturais. Rio de Janeiro: Vozes, 2014. p. 103-133.

HARTOG, François. Regime de Historicidade [Time, History and the writing of History KVHAA Konferenser 37: 95-113 Stockholm 1996]. Disponível em:

<https://pos.historia.ufg.br/up/113/o/Fran\%C3\%A70is_Hartog_-

_Regime_de_Historicidade_(1).pdf>. Acesso em 07 de jan. de 2017.

HARTOG, François. Aristóteles e a história, mais uma vez. História da Historiografia. Ouro Preto, $\mathrm{n}^{\circ}$ 13, p. 14-23, dez. 2013.

LEMOS, André et al. Cidade, tecnologia e interfaces: análise de interfaces de portais governamentais brasileiros. Uma proposta metodológica. Revista Fronteiras - Estudos Midiáticos, São Leopoldo: Unisinos, v. 2, p. 116-137, jul./dez.,2004. Disponível em: <http://www.revistas.univerciencia.org/index.php/fronteiras/article/view/3096/2906>. Acesso: 8 jan. 2013.

MAGNO, Maria Ignês Carlos. 1984 e Nós. Um filme, dois romances e a sociedade atual Comunicação \& Educação, São Paulo, v. 19, n. 1, p. 145-154. 2014. Disponível em: <http://www.revistas.usp.br/comueduc/article/view/78931>. Acesso em: 05 de fevereiro de 2017.

MARTINS, Marcos Lobato. História regional. In: PINSKY, Carla Bassanezi (Org.). Novos temas nas aulas de história. 2. ed. São Paulo: Contexto, 2010. p. 135-152.

ORLANDI, Eni Puccinelli. Análise do discurso: princípios e procedimentos. Campinas. SP: Pontes, 1999.

RICOUER, Paul. A memória, a história, o esquecimento. Campinas: Edunicamp, 2007. p. 143-301.

SANTHIAGO, Ricardo. Duas palavras, muitos significados: alguns comentários sobre a história pública no Brasil. In: MAUAD, Ana Maria; ALMEIDA, Juniele Rabêlo de; 
SANTHIAGO, Ricardo (Orgs.). História Pública no Brasil: sentidos e itinerários. São Paulo: Letra e Voz, 2016. p. 23-36.

SCHITTINO, Renata. O conceito de público e o compartilhamento da história. In: MAUAD, Ana Maria; ALMEIDA, Juniele Rabêlo de; SANTHIAGO, Ricardo (Orgs.). História Pública no Brasil: sentidos e itinerários. São Paulo: Letra e Voz, 2016. p. 37-46.

SILVA, Tomaz Tadeu da. A produção social da identidade e da diferença. In: SILVA, Tomaz Tadeu da. (Org). Identidade e diferença: a perspectiva dos estudos culturais. Rio de Janeiro: Vozes, 2014. p. 73-102.

SOUSA, Jorge Pedro. Introdução à análise do discurso jornalístico impresso: um guia para estudantes de graduação. Florianópolis: Letras Contemporâneas, 2004.

WOODWARD, Kathryn. A identidade e a diferença: uma introdução teórica e conceitual. In: SILVA, Tomaz Tadeu da. (Org). Identidade e diferença: a perspectiva dos estudos culturais. Rio de Janeiro: Vozes, 2014. p. 7-72.

Recebido em 26/11/2016 Aprovado em 29/04/2017

Universidade do Estado de Santa Catarina - UDESC Programa de Pós-Graduação em História - PPGH Revista Tempo e Argumento Volume 09 - Número 20 - Ano 2017 tempoeargumento@gmail.com 